\title{
HEMIMELIC SKELETAL DYSPLASIA
}

\author{
H. M. Saxton and J. A. Wilkinson, London, England
}

Dysplasia epiphysialis hemimelica is the name given to a rare disorder of epiphysial growth. The features were described by Trevor (1950) and Fairbank (1956), who between them collected twenty-four cases. Other workers have given similar accounts of the condition (Ingelrans and Lacheretz 1953; Donaldson, Sankey, Girdany and Donaldson 1953; D’Angio, Ritvo and Ulin 1955; Keats 1957; Moseley 1957; Fulton 1958; Wheble and Connell 1958; Rechnagel 1960). In all cases there was a disorder of epiphysial growth usually involving the lower limb and with a characteristic hemimelic distribution. The present case is recorded because of widespread involvement of the epiphyses affecting both upper and lower limbs, which has never before been reported, and an associated metaphysial dysplasia.

\section{CASE REPORT}

A Jamaican boy of fifteen months was seen because of progressive bowing of his left leg. He could stand but not walk. His left leg was laterally rotated and the apparent bowing was due to flexion deformities of the hip and knee. The hip could be flexed from 30 to 80 degrees:

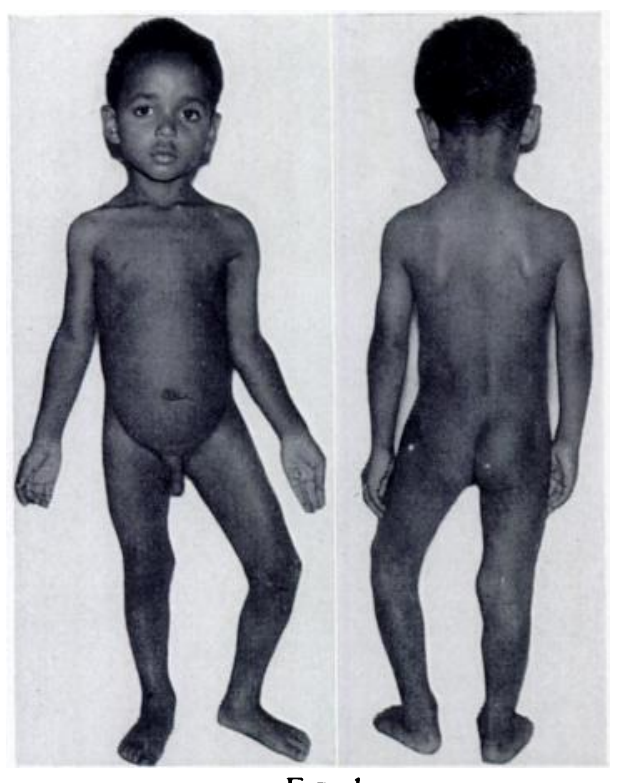

FIG. 1

The boy at $3 \frac{1}{2}$ years. The left arm and leg are longer than the right and there is a flexion deformity of the left hip and knee. The pigmented area can be seen above the left hip. extension of the knee was limited by 25 degrees, but the range of flexion was normal. A large café-au-lait patch was present on the left buttock. but there was no other evidence of neurofibromatosis, and there was no precocious puberty. His father (aged thirty-five) and mother (aged thirty), four brothers and three sisters were normal and there was no familial history of skeletal deformities.

For the next two years the boy was seen every two months and developed lengthening of the left arm and leg, both of which grew an inch longer than the normal side. By the time he was three and a half the left thigh was fixed in 30 degrees of flexion and abduction and almost 80 degrees of lateral rotation (Fig. 1). The rotation and abduction deformities were corrected by subtrochanteric femoral osteotomy and at the same time a central biopsy of the femoral neck and head was taken by drilling a cannula upward from the osteotomy site.

Histological examination showed that the cylindrical specimens contained both bone and cartilage (Fig. 2). The cartilage cells were irregular in shape and in one place they were arranged in columns suggestive of epiphysial cartilage, but in general these cells had no orderly arrangement. Arising from the irregular masses of cartilage were areas of bone which were associated with bone marrow in some places. Much of the bone was necrotic, but where it was viable it consisted of islands of compact bone with osteoblastic activity at the edges and mature osteocytes in the centres. There was 


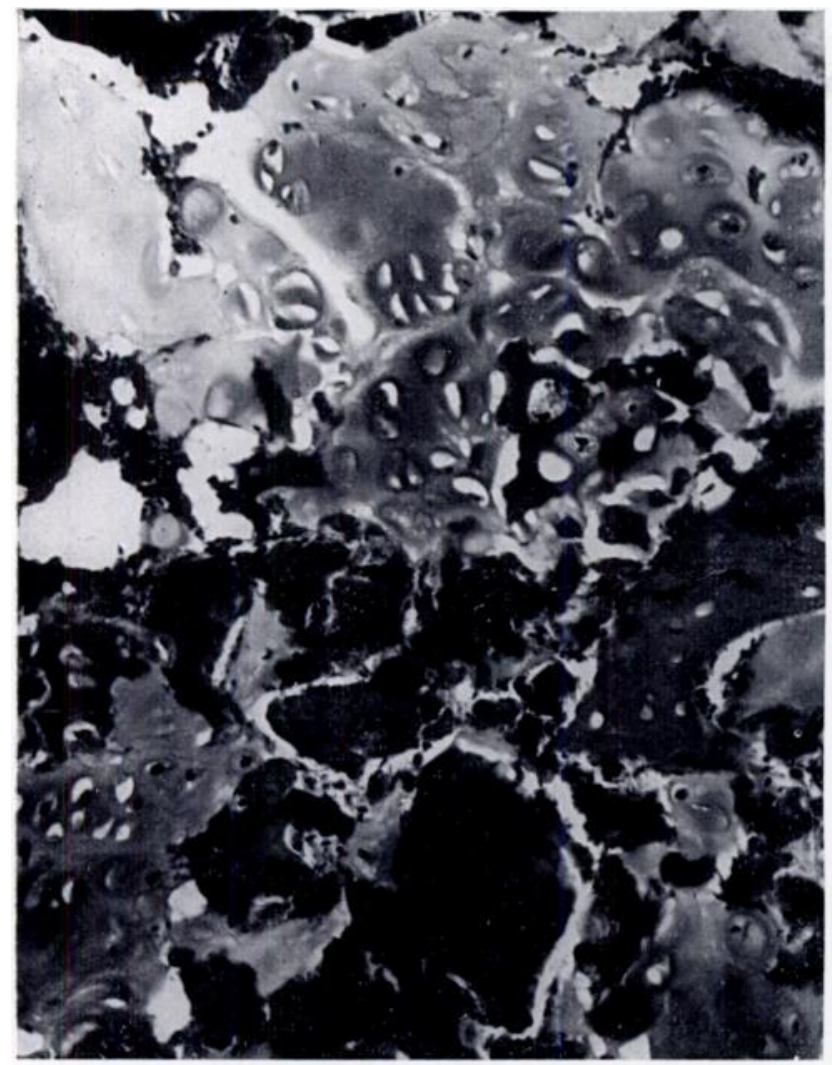

FIG. 2

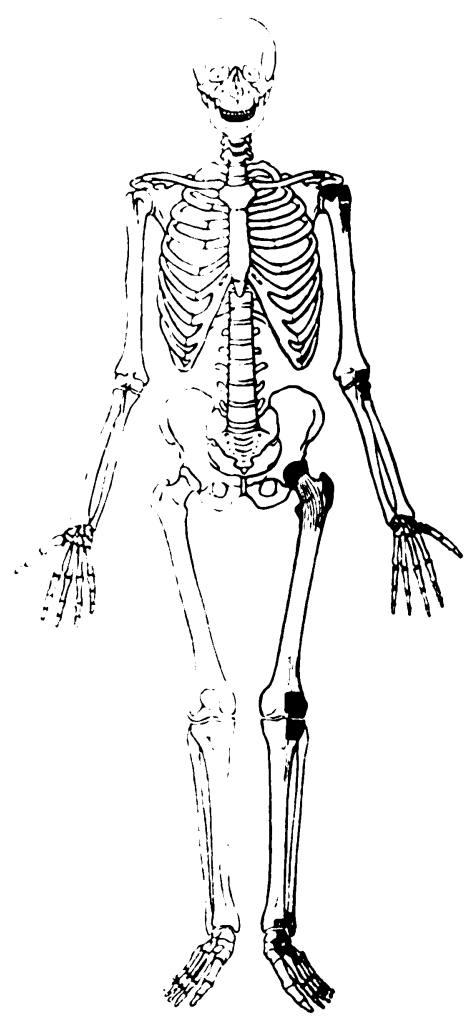

FIG. 3

Figure 2-Photomicrograph of the biopsy specimen showing irregularly arranged cartilage columns with small islands of compact bone. (Haematoxylin and eosin, 150.) Figure 3-Diagram showing the hemimelic distribution of the epiphysial and metaphysial lesions.

no evidence of bony, as opposed to cartilaginous, cellular division and the whole histological picture resembled that of an osteochondroma.

Radiological features-The skeletal survey is recorded in Figure 3.

Left hip-At first the capital epiphysis was enlarged and was covered by a sloping acetabular roof. Multiple foci of ossification were present throughout the whole femoral head and the neck was wider than normal. Both trochanters were enlarged and irregular (Fig. 4). During the next two years the capital epiphysis grew to many times the normal size and became deformed. Its peripheral ossification appeared to be broken up by clear areas, presumably of overgrown cartilage; at the same time it became difficult to distinguish the epiphysial plate. The femoral neck grew longer and wider than normal and translucent irregular areas with longitudinal striae appeared in the proximal metaphysial region (Fig. 5).

Left knee-When first seen, the typical appearances of the disorder were present in the lateral halves of the lower femoral and upper tibial epiphyses (Fig. 6). During the period of observation these ectopic foci of ossification led to greater bone overgrowth and deformity, associated with increasing irregularity of the lateral halves of the respective epiphysial plates (Fig. 7). Again, atypical metaphysial changes appeared resembling the cords of translucent column seen in dyschondroplasia.

Left ankle and foot-Irregular areas of ossification were present in the lower fibular epiphysis. On the lateral side of the talus there was an irregular exostosis (Fig. 8). The centres of ossification of the lateral half of the navicular and the second cuneiform bones had appeared prematurely (Fig. 9). They eventually became abnormally large and irregular in shape. The 


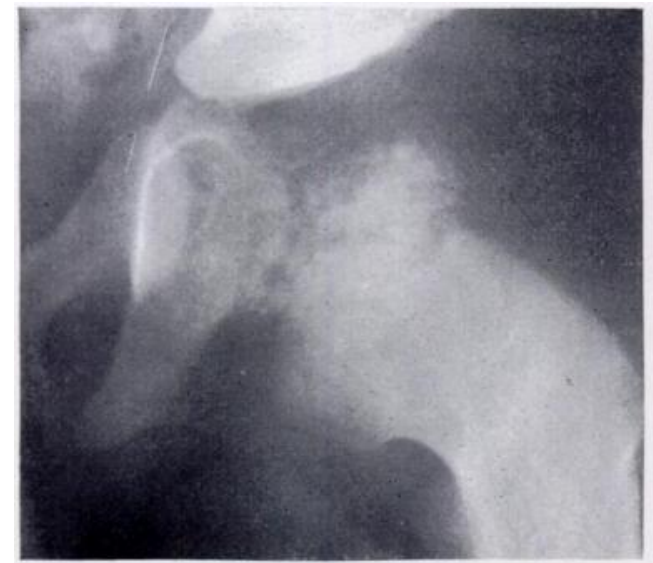

FIG. 4

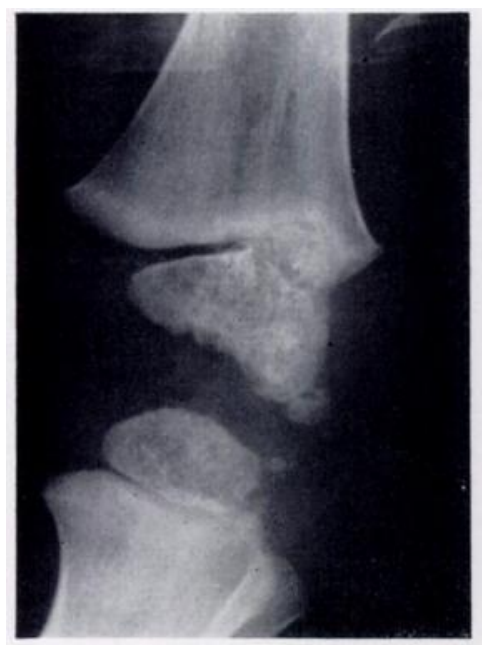

FIG. 6

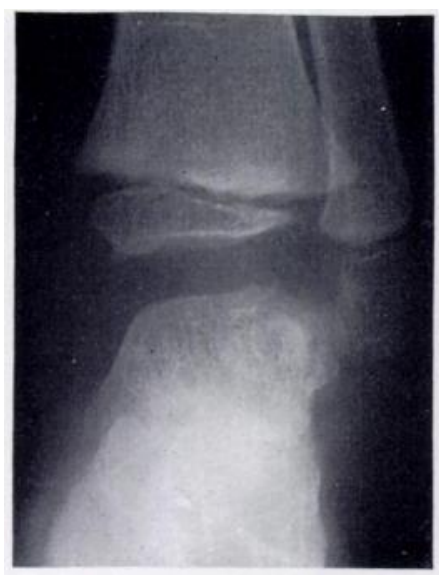

FIG. 8

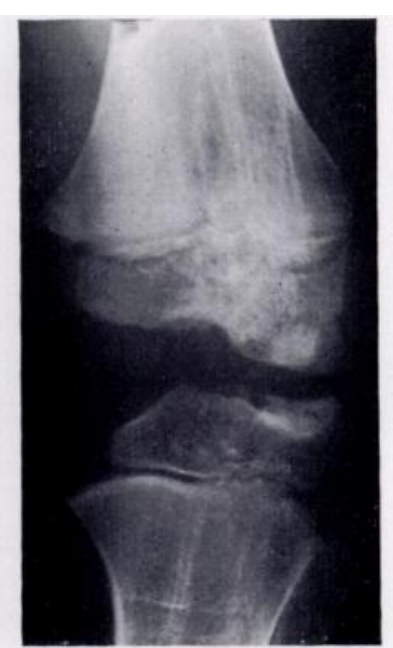

FIG. 7

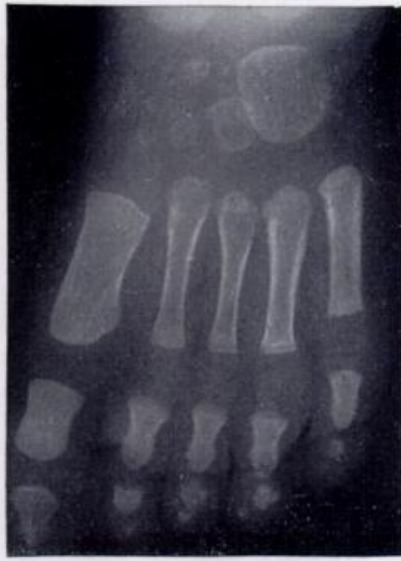

FIG. 9

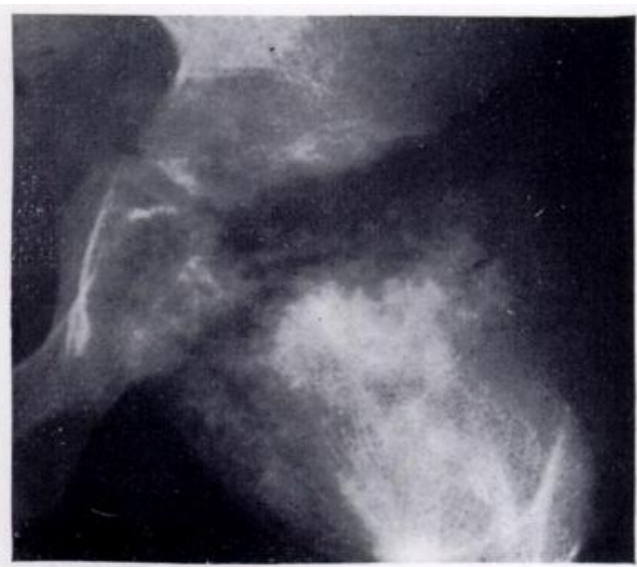

FIG. 5

Fics. 4 To 7

Figure 4-Radiological changes in the left femur at 15 months Figure 5-Multiple foci of ossification, with involvement of the capital epiphysis, the metaphysis and the trochanters at 3 ! years. Figure 6-Radiological changes in the left knee at 15 months. Figure 7-The lateral halves of the distal femoral and proximal tibial epiphyses are involved, with striae in the metaphysial regions, at $3 !$ years

Figure 8-Radiological changes in the left ankle. At 3. years the lateral half of the talus and distal fibular epiphyses are involved; note the irregular exostosis on the lateral aspect of the talus. Figure 9Radiological changes in the left foot at 15 months. Figure 10-Premature ossification is present in the navicular and second cuneiform bone with involvement of the lateral two metatarsals and phalanges at $3 \frac{1}{2}$ years.

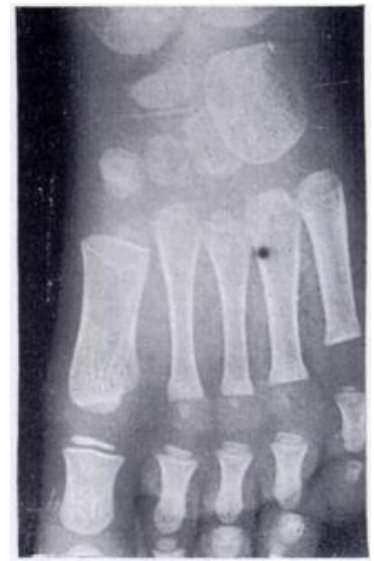

FIG. 10 
lateral two metatarsal bones and their proximal phalanges appeared slightly enlarged (Fig. 10). Left shoulder-An early radiograph revealed premature ossification in the greater tuberosity of the humerus with the lateral third of the clavicle thickened and upwardly displaced. During

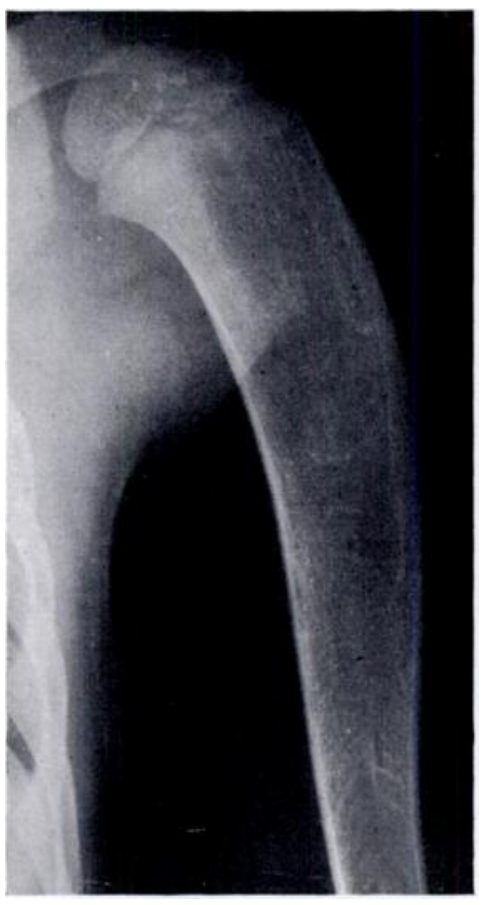

FIG 11

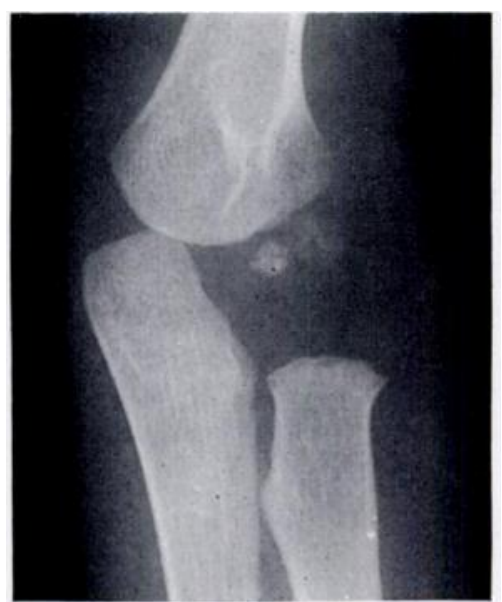

FIG. 12

Figure 11 -Left humerus at $3 \frac{1}{2}$ years. There is irregular ossification in the lateral half of the proximal epiphysis, with striae in the lateral metaphysis. The convexity of the bowed shaft is on the side of the lesion indicating local overgrowth. Figure 12-Left elbow at $3 \frac{1}{2}$ years. There is involvement of the capitulum, and the neck of the radius is thickened.

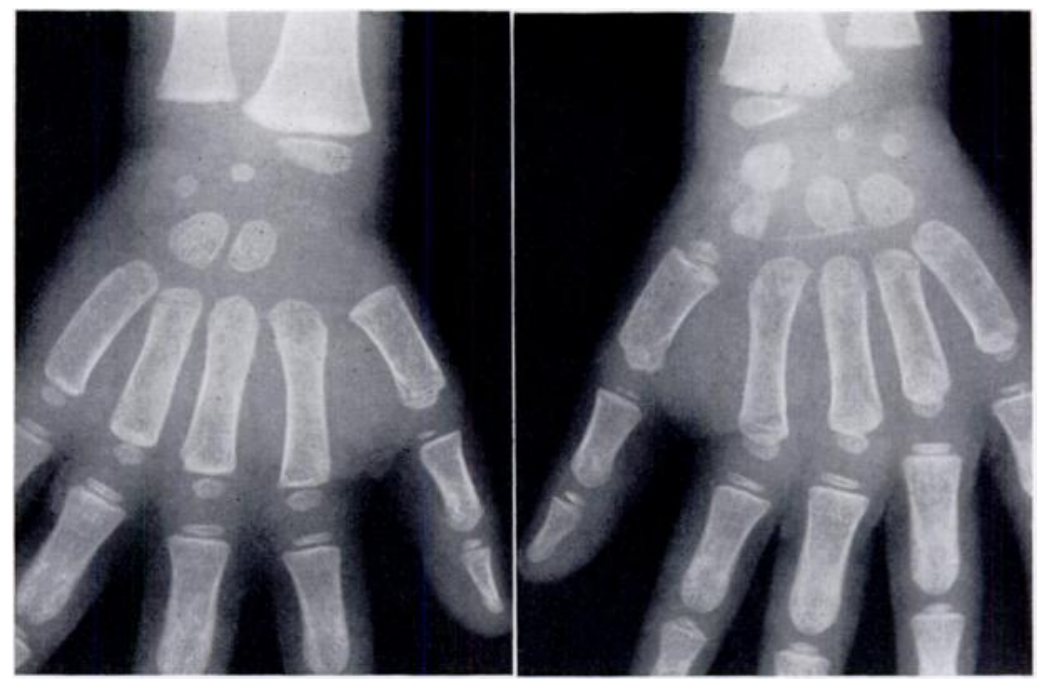

FIG. 13

Radiograph of both hands at $3 \frac{1}{2}$ years. There is premature ossification in the scaphoid, trapezium and proximal epiphysis of the first left metacarpal bone, which is also thickened.

the next two years there was excessive growth of the lateral part of the upper humeral epiphysis. The adjacent metaphysis became striated as in the femur, and there was local overgrowth which produced lateral bowing of the humeral shaft (Fig. 11).

VOL. 46 B, No. 4, NOVEMBER 1964 
Left elbow-Irregular ossification in the capitulum was associated with thickening of the neck of the radius (Fig. 12), and at the wrist the radius appeared abnormally long in relation to the distal end of the ulna (Fig. 13).

Left wrist-Premature ossification appeared in the scaphoid, the trapezium and the proximal epiphysis of the first metacarpal bone, the shaft of which seemed to be thicker than the one in the right hand (Fig. 13).

\section{DISCUSSION}

This case shows features which are typical of the growth disorder formerly described under the headings " la tarso-megalie" (Mouchet and Belot 1926), "tarso-epiphysial aclasis" (Trevor 1950) and "dysplasia epiphysialis hemimelica" (Fairbank 1956). The particular interest of this case lies, however, in the atypical features which place it outside the scope of these titles. The typical features will be discussed and the atypical aspects considered in detail. Typical features-These include the sex, as boys are more commonly affected than girls, the age of presentation and the mainly hemimelic distribution of the lesions. The epiphysial changes in the left ankle and knee are characteristic in their appearance, but the metaphysial involvement of the knee is atypical. Irregular outgrowths on the talus have been seen in many cases. Premature appearances of ossification centres in the tarsus (Trevor 1950) and carpus (Fairbank 1956) have also been reported, with involvement of the metatarsal and metacarpal bones.

Previous histological studies have been confined to the examination of excised bony outgrowths (Trevor 1950, Fairbank 1956, Rechnagel 1960). This is the first report of specimens taken from the centre of an affected epiphysis and the metaphysial region. At both sites the cellular changes were identical to those already described.

Atypical features-Involvement of the entire capital epiphysis of the femur is an exception in that the disorder exceeds its usual hemimelic distribution. Fairbank (1956) reported a similar case but the details were not published. The extent of the overgrowth in this case must be quite unusual. The growth of irregular cartilaginous masses in the epiphysis appeared to have penetrated the epiphysial plate and invaded the metaphysial region.

Lengthening of the limb is unusual in dysplasia epiphysialis hemimelica and shortening is a more common manifestation in metaphysial dysplasia and dyschondroplasia. In our case it appears that a disorder like that of the epiphyses also involves the epiphysial plates, as the latter are responsible for diaphysial growth and metaphysial changes. Although Trevor stressed the absence of metaphysial changes in tarso-epiphysial aclasis, Fairbank (1956) reported a case in which involvement of half the epiphysis of the femoral head was associated with lengthening, widening and valgus deformity of its neck; he and also Moseley (1957) reported cases showing enlargement and irregularity of a lower fibular epiphysis with thickening of the metaphysis.

Involvement of the upper limb has only been reported in two previous cases (Fairbank 1956) and neither of them had lower limb lesions. Indeed, affection of only one limb has been regarded as a constant feature of the disease, the only previous exception being in a case mentioned by Fairbank, in which changes in the opposite hip were of uncertain relevance. This present case is also the first with involvement of both proximal and distal humeral epiphyses; the latter is more significant as the elbow usually remains free from the changes of most developmental errors (Fairbank 1951).

Etiology-Harris (1933) first described the pattern of peripheral growth and central ossification in an epiphysis. According to his account, growth in an epiphysis occurs by division of the cartilaginous cells from a mitotic annulus at the periphery of the cartilage. Trevor (1950) suggested that tarso-epiphysial dysplasia arose because some of the cartilage cells in the mitotic annulus retained their power of division by failing to undergo the normal process of degeneration, calcification and ossification. Histological studies on the affected capital epiphysis in our case support this proposition as the particular cartilage cells showed a loss 
of polarity from excessive activity. As mitotic division of cartilage cells also occurs in the epiphysial plate and is normally followed by the same processes of degeneration and calcification (Harris 1933), the metaphysial abnormality in this case may well be the result of a similar retention of their power to divide, as postulated by Trevor for the epiphysis. The natural resistance of the cartilage cells of the epiphysial plate to degeneration and ossification would lead to the striated appearances of the metaphysis, associated with widening and lengthening of the affected bone.

Striated areas, due to a columnar arrangement of cartilage-filled clear spaces in the metaphyses, is one of the typical radiological features of dyschondroplasia. The general manifestations of this rare developmental error, however, are unlike those in the case under discussion in two respects: premature ossification of the epiphyses does not occur in dyschondroplasia, and there is usually shortening of the affected limb. Fairbank's description (1951) of the production of deformities in dyschondroplasia is: "when one half of the metaphysis is occupied by columns of cartilage to a greater extent than the other, the rate of growth at the corresponding half of the epiphysial line is often retarded. In this way deformities such as genu valgum may develop." By contrast, in this boy the convexity of the bowed humeral shaft was on the same side as the lesion (Fig. 11), indicating an increased rate of growth in the corresponding half of the epiphysial plate. The striations in dyschondroplasia are also caused by a developmental fault in the epiphysial plate, nests of cartilage failing to undergo degeneration and calcification (Fairbank 1951), but the cartilage cells do not appear to retain the power of mitotic division, as postulated in this form of epiphysio-metaphysial dysplasia.

\section{SUMMARY}

1. A case is reported of a Jamaican boy of fifteen months with typical and florid manifestations of dysplasia epiphysialis hemimelica associated with a number of atypical features not previously recorded.

2. The progress of the disorder over a limited period of two years is described and the development of the atypical features is discussed.

We wish to express our gratitude to Mr H. E. Harding for his help and for access to the records of his patients. We are indebted to Dr Ian Dawson for the photomicrograph and histological studies, and to $\mathrm{Mr} \mathrm{H}$. Jackson Burrows for his advice on the preparation of this paper. The illustrations were produced by the Photographic Department of the Westminster Hospital and Medical School.

\section{REFERENCES}

D'Angio, G. J., Ritvo, M., and Ulin, R. (1955): Clinical and Roentgen Manifestations of Tarso-epiphyseal Aclasis. American Journal of Roentgenology, 74, 1,068.

Donaldson, J. S., Sankey, H. H., Girdany, B. R., and Donaldson, W. F. (1953): Osteochondroma of the Distal Femoral Epiphysis. Journal of Pediatrics, 43, 212.

Fairbank, Sir T. (1951): An Atlas of General Affections of the Skeleton. Edinburgh and London: E. \& S. Livingstone Ltd.

Fairbank, T. J. (1956): Dysplasia Epiphysialis Hemimelica. Journal of Bone and Joint Surgery, 38-B, 237.

Fulton, H. (1958): Dysplasia Epiphysialis Hemimelica. American Journal of Diseases of Children, 95, 276.

Harris, H. A. (1933): Bone Growth in Health and Disease, p. 143. London: Humphrey Mitford Oxford University Press.

Ingelrans, P., and Lacheretz, M. (1953): A propos d'un cas de chondrodystrophie épiphysaire. Revue de Chirurgie Orthopédique, 39, 242.

Keats, Theodore E. (1957): Dysplasia Epiphysialis Hemimelica. Radiology, 68, 558.

Moseley, J. E. (1957): Dysplasia Epiphysealis Hemimelica (Tarso-epiphyseal Aclasis). Journal of the Mount Sinai Hospital, 24, 514.

Mouchet, A., and Belot, J. (1926): La tarsomégalie. Journal de Radiologie et d'Électrolcgie, 10, 289.

Rechnagel., K. (1960): Dysplasia Epiphysialis Hemimelica. Acta Orthopaedica Scandinavica, 29, 236.

Trevor, D. (1950): Tarso-Epiphysial Aclasis: A Congenital Error of Epiphysial Development. Journal of Bone and Joint Surgery, 32-B, 204.

Wheble, V. H., and Connell, M. C. (1958): Dysplasia Epiphysialis Hemimelica. British Journal of Radiology, $31,637$.

VOL. 46 B, NO. 4, NOVEMBER 1964 